\title{
1
}

\section{PERSPECTIVES AND CHALLENGES OF ORGANIZATIONAL INFORMATION SYSTEMS IN THE CONTEXT OF GLOBALIZATION}

Introduction to the Theme

Mikko Korpela ${ }^{1}$, Ramiro Montealegre ${ }^{2}$ and Angeliki Poulymenakou ${ }^{3}$

${ }^{1}$ University of Kuopio, Finland; ${ }^{2}$ University of Colorado, USA and Instituto de Empresa, Spain; ${ }^{3}$ Athens University of Economics and Business, Greece

\section{INFORMATION SYSTEMS AND GLOBALIZATION}

In this book, the context and process of globalization are understood as a complex web of increasingly deepening interrelationships among countries, organizations, social groups, and individuals. Information and communication technologies (ICTs) are seen as a vital part of the globalization agenda.

Falling trade barriers - the European Union, the North American Free Trade Agreement, Mercosur - global capital markets, global communication, global customers, a changing regulatory environment, technologies that support a span of control transcending national boundaries, and the need to find revenue growth in new markets are all driving corporations to globalize. More importantly, societies, social groups, governments, policymakers, non-profit organizations, and individuals are all increasingly challenged by changes in their professional, social and personal spaces and activities, brought about by connectivity and digitization.

The information systems research agenda has been dealing for a number of years now with these issues. Globalization is a force of unification and conformity - as seen, for example, in the proliferation of global brands such as Nike, Coca-Cola, McDonald's. Globalisation is also a force of divide, diversity, and social struggle for prosperity. Despite dominant policy and managerial rhetoric, not all globalisation messages can be considered as positive, and the multifaceted impacts of the globalisation process on local 
contexts are far from being well understood, adequately researched, or dealt with in a balanced manner. The multidisciplinary work carried out on the societal and organisational implications of information systems has significant contributions to make in deepening our understanding on these new phenomena and the changes they bring about.

In 1973, the Secretary-General of the United Nations reported to the General Assembly that the number of computers was about 80,000 in the USA, 11,000 in Japan, 7,000 in the UK, 1,200 in Brazil, 200 in India and 30 in Nigeria. The report concluded in the following main points about the role of "the computer" in global socio-economic development (United Nations, 1973):

In looking to the computer as an aid to development, three points are particularly noteworthy. First, it must be emphasized that computers are only tools. [...] Their effectiveness depends on those who plan, approve, implement, manage, monitor and evaluate activities in which the computer is involved. The human element, in short, is the sine qua non for the use of this technology. Secondly, computers and their technology are costly, in terms of both the hardware and software involved and the education, training and retraining of personnel at all levels. Thirdly, the computer and its technology require and generate a broad socioeconomic environment [...].

Finally, [...] the computer is not a panacea for administrative and development problems. Possession of a computer may at first create at least as many problems as it solves. Its use requires highly trained systems designers, analysts, programmers and operators. Without such trained personnel, the computer cannot be used effectively. It also requires reliable data which have to be collected and transcribed suitably. The computer demands a considerable infrastructure, or else it cannot function.

Today, thirty years later, we speak about information systems instead of "the computer," acknowledging the need to focus on the interaction between technology and its context. Despite the dramatic development in technology, however, the conclusions of the United Nations report are still surprisingly valid. ICTs have an enormous potential for socio-economic and human development, but only when applied meaningfully in organizational and societal activities - as information systems - by knowledgeable people, and supported by appropriate infrastructures.

The Internet has now reached all countries, but the relative difference between countries in the number of Internet users per capita is as high, if not higher, than the difference in mainframes thirty years ago. Optimism is tempered by the awareness that most fundamental and technological progress is 
still "outside and has to be imported," and that a process of "haves and havenots" polarization is underway that could exacerbate differences among national groups, aggravating the already existing gaps. This raises an important question about the overall ability of relevant actors to exploit the malleability of these new technologies and to implement applications - nurtured in the proper social, cultural, and technological environment - to capitalize on their full potential.

This was what motivated two working groups of the International Federation for Information Processing (IFIP) to call for a conference to discuss the perspectives and challenges of information systems in the context of globalization in Athens, Greece, in June 2003.

\section{BACKGROUND OF THE CONFERENCE}

IFIP is a non-governmental, non-profit umbrella organization for national societies working in the field of information processing. It was established in 1960 under the auspices of UNESCO as an aftermath of the first World Computer Congress held in Paris in 1959. IFIP's principal aims were and are to foster international cooperation, to stimulate research, development and applications, and to encourage education, dissemination and exchange of information on all aspects of computing and communication.

In 1977, IFIP established a working group concerned with "the interaction of information systems and the organisation." The working group, WG 8.2, seeks to generate and disseminate knowledge about and improve understanding of the role and impact of information technology across a range of social levels (society, organization, individual) and across a diversity of spheres (marketplace, workplace, home, community). One of the most influential events organized by the WG 8.2 was a conference in Manchester in 1984 on research methods in information systems, which became a breakthrough for non-positivist research approaches (Mumford et al., 1985). WG 8.2 has ever since been the home for interpretative and critical research on information systems as social phenomena. Although some of its conferences have explicitly included a societal dimension (Avison et al., 1993), the focus of the working group has been on the organizational and workgroup levels of analysis. The overwhelming majority of WG 8.2 members are from North America, Europe and Australia. The spirit of the working group has thus been favourable to societal and cultural diversity, but research in its realm has not been geographically global in scope.

Another IFIP working group, WG 9.4 on "social implications of computers in developing countries", emerged from a working conference in New Delhi in 1988 (Bhatnagar and Bjørn-Andersen, 1990). WG 9.4 has 
always emphasized a social viewpoint on the application of ICTs, and therefore the focus has been on organizational information systems in addition to national issues of ICT policy. The working group has been the main forum for information systems research on and in developing countries, but also for more general discussion on the role of ICTs in development and the need for societal, cultural, and organizational adaptation in information systems research and development (Avgerou and Walsham, 2000).

In the WG 8.2 conference in Aalborg in 2000, Geoff Walsham reviewed the state of information systems research on issues of globalization. $\mathrm{He}$ stated that although globalization was a popular buzz word, most of the existing research was conducted in North America and Europe on the organizational and sub-organizational levels, implicitly assuming that the results were universally applicable. He urged information systems researchers around the globe "to study particular individuals, groups, organizations, or societies in detail, and in context" (Walsham, 2000).

Following Walsham's call, the idea of a joint conference by WG 8.2 and WG 9.4 was pushed forward by the chairpersons of the WGs, David Avison and Chrisanthi Avgerou. They searched for possible sites and organizers for the conference. In July 2001, a proposal by the Athens University of Economics and Business was approved, with Angeliki Poulymenakou as the Organizing Chair. Ramiro Montealegre was appointed as Program Co-Chair representing WG 8.2 and Mikko Korpela representing WG 9.4. The three conference chairs worked closely together as a team, supported by Geoff Walsham as the General Chair and the WG 8.2 and 9.4 chairs.

The conference call focused on organizational information systems from a global perspective. Contextually aware studies of information systems from all parts of the world form the basis for comparisons and inferences from a global viewpoint in the conference. "Globalization" is seen as a contradictory process, which may imply increased transnational uniformity but also increased diversity, through increased interconnectedness of local actors.

\section{THE REVIEW PROCESS AND THE CONFERENCE}

The Call for Papers for this conference attracted 111 paper and panel submissions on a diverse set of topics relating to the conference theme. Each paper was reviewed by two anonymous reviewers, who represented both WG 8.2 and WG 9.4 viewpoints. In case the reviewers' recommendations differed, the three conference chairs provided a further review. At the end of the review process, we had as many as 52 papers and 2 panel proposals that were recommended to be presented in the conference. The increased interest 
in the conference urged us to accept them. This is an unusually large number of papers for a typical WG 8.2 or 9.4 meeting, but the joint nature of the conference further justified it.

However, that many papers could not be accommodated in the proceedings. The selected papers varied significantly both in terms of topics but also in terms of the 'maturity' of the work, according to our reviewers' comments. We then decided to select 26 papers and 2 panels to be included in this book, and to include the remaining 26 papers in an electronic supplement that is available to the conference participants on CD-ROM. The electronic papers will be submitted to various information systems journals for potential publication afterwards in an edited form. All the papers selected for this book were also edited by the authors according to the reviewers' comments, and the final papers were accepted by the proceedings editors.

In addition to the selected presentations and panels, the conference programme includes keynote presentations by Prof. Saskia Sassen and Prof. Geoff Walsham, as well as an invited panel.

We are very pleased with the originality, diversity, and quality of the papers selected and we hope that the reader will feel equally satisfied. The selected papers reflect the diversity of information systems research with respect to research approaches, theoretical traditions, research subject, and geographical focus. We have papers employing diverse research methods, drawing on multiple analytical theories, and representing the various world continents.

\section{OVERVIEW OF THE PAPERS}

We provide below an overview of the papers accepted for publication in this volume. The papers exemplify an extremely rich and diverse array of themes, theoretical approaches, local contexts and practical implications currently researched under the conference's general theme.

Notably, through the research presented in this volume, we gain insights in local contexts that are comparably less frequently researched through an information systems perspective. Moreover, even when well-researched contexts such as the UK are the basis for empirical work, the research reported in this volume casts a different eye on them, focusing mainly on issues that transcend the usual managerial and economic welfare maxims.

Empirical research reported in this volume has been conducted in the following national, regional and local contexts (listed in alphabetical order): Australia (including aboriginal communities), Brazil, China, Ecuador, Egypt, India, Ireland, Jordan, Korea, Malaysia, Maldives, Mozambique, New Zealand, Peru, Portugal, Russia, Scandinavia, Spain, South Africa, UK and the USA. The electronic supplement adds Argentina, Bangladesh, Canada, 
Caribbean, Chile, Cuba, The Gambia, Ghana, Greece, Kenya, Nepal, Nigeria, Oman, Philippines, Venezuela and Yugoslavia to the list.

The topics of research covered in this volume span the micro (individual), meso (organisational), and macro (society) levels. Despite the obvious risks embedded in any attempt to group the individual pieces of work under any classification scheme, we believe there is merit in eliciting some generic themes under which research documented in this volume can be seen to unfold. We have opted against a theory versus practice divide, as this would be rather artificial - even papers that do not have a particular real life context documented and analysed have a strong element of practice in terms of their specific focus on particular implications for it. We have also opted against a "Western" vs. "non-Western" divide, to highlight the diversity of contexts within each theme.

We see five main domains where the dynamic interplay between the global and the local is studied in relation to information systems in the works included in this volume:

1. Work practices and their transformation

2. Organizations, corporations and institutions

3. ICT industries and systems development

4. Societal dynamics

5. Cultural, philosophical and policy issues

In what follows, we present a brief overview of the papers in this volume according to the above generic categories of topics, followed by the panels.

\subsection{Work Practices and their Transformation}

Kathy McGrath examines the omni-present theme of organizational modernization through ICT adoption. She is applying a discourse-analytic perspective on the emergency services of the UK National Health Service. Her analysis shows how calls for cultural change quickly converge on narrowly conceived target-meeting efforts both at the ministerial and at the managerial level in her research context. Participants in the local context do not accept framing modernization in such terms, as McGrath shows.

Emilio Mosse and Sundeep Sahay 'unpack' the relationship between communication practices and information flows in their study of community health information systems in Mozambique. They use Castell's metaphor of counter networks to analyze how information processing practices are influenced by communication practices across various levels of administration and how the marginalization of groups and regions can be avoided when implementing such systems.

Jens Pors and Jesper Simonsen's work studies the relationship between work practice and IT artefact in the context of a groupware application adoption by distributed work teams. Their case setting is a financial 
institution, spanning four countries. They review the fundamental concept of coordination, as this is manifest in the artefact design as well as in the intentions to support collaborative work. Their extensive, multifaceted case study analysis leads them to suggest six generic factors influencing the integration of such technology into a work practice. These factors address management, membership, evaluation potential, reduction of complexity, exemplification of experiences, and active facilitation.

Helen Richardson applies Bourdieu's critical social theory on the study of Customer Relationship Management (CRM) technology utilization. Her context is CRM used in Call Centres serving a variety of client firms in northwest England. Richardson discusses the role of these systems as purveyors of organizational intelligence and identifies internal conflicts inherent in their use: worker control seems to take precedence over worker flexibility, or empowerment. Richardson uses critical social theory for the interpretation of social relations around CRM system use, in her context. Her interpretive lens helps us visualize some of the relevant dynamics of the social situation she examines such as the accommodation and bypassing of formal management arrangements imposed through the technology, the incongruence of 'knowledge management' aspirations through mere passive recording of data, and the aggressive management tactics of domination poorly concealed under standardization claims.

Robert Tucker and Niki Panteli report on research dealing with the issue of trust in virtual teams. They challenge current understandings which claim that trust is created 'swiftly' in such environments and they elaborate on the difficulties created by conflict and power differentials. Their empirical study on eighteen virtual teams stresses the value of shared goals formulation, which they frame as a continuous, multifaceted process throughout a virtual team's 'life'.

In the conference, this theme is augmented by the electronic papers by Helen Hasan and Kathryn Crawford on distributed communities of learning and practice, Dawn Jutla et al. on information technology innovation, Adekunle Okunoye on knowledge management, Lucy Firth et al. on community health information systems, as well as Kostas Samiotis and Angeliki Poulymenakou on knowledge management interventions.

\subsection{Organizations, Corporations and Institutions}

Mariyam Adam and Michael Myers interpret the implementation of an Information System for the Maldives Customs Service as a neo-colonialist attempt for domination of the global technological onto the local context. In their case study they illustrate neo-colonialist behaviour in the attempts to streamline local practices with international policy directives issued by the 
projects' funding body. The study reflects on the potential impacts of such 'globalization facilitated by software'.

Nabeel Al-Qirim studies ICT innovation adoption in small and medium enterprises in the context of three electronic commerce adoption cases in New Zealand. The conceptual framework driving the empirical research is developed through a synthesis of Rogers' diffusion of innovation theory with relevant extant theory on ICT adoption. The empirical work he conducted corroborated some of the factors in the framework, while many others were not supported, partly due to a tendency of the firms to treat electronic commerce initiatives as the ground for experimentation rather than as a vehicle for strategic advantage.

Jose Esteves, Joan Pastor and Joao Carvalho document a case of ERP implementation in a Portuguese medium sized enterprise. They develop a comprehensive factor model for the implementation process in such contexts, which they then populate with data from their case with special emphasis on organizational actions and reactions over the project's duration. Their findings are further interpreted from a cultural context perspective leading the authors to conclude that further research within this line of thinking is capable of shedding light into cases of problematic ERP adoption in local contexts diverging from the common corporate mould.

Wei Liu and Chris Westrup study globalization by looking at how Multi-National Enterprises use ICTs for organizing. They compare a UK with a China based venture to discuss cross-cultural coordination and control. Their main conclusions show that far from introducing managerial uniformity by alleviating time and distance barriers, and by enforcing standard practices, the use of ICTs necessitated human agency for coordination as well as for exploitation of available management facilitation features. In non-Western contexts, the seeming 'closeness' through ICT warrants reinterpretation based on local context characteristics.

Esselina Macome studies IS implementation with an emphasis on the global-local context debate within a case where the system was specifically earmarked as a modernization initiative. The suppliers and implementers of an invoicing system represent 'global' in her study in the Mozambican Electricity Company, while 'local' is represented by the company's IT and management staff and the system's end users. Using Rogers' diffusion of innovation theory coupled by an actor-network theory interpretation, she draws a number of recommendations for implementation team formation and membership, accommodation of changes to work practices, and organizational stabilization efforts.

Garry Pan, Shan Pan, Xin-Xin Chen, and Donal Flyn relate global IT products and local implementation contexts in their study of ERP implementation in China. They provide insights on the experiences of five firms in this rarely researched local context. Their analysis is focusing on alignment issues regarding management and operational process features on 
the one hand, and package features on the other. Their study, still at the exploratory stage, suggests that the usual difficulties and dilemmas encountered by western economy firms when implementing ERP, are further precipitated in the Chinese context due to an ambient sense of uncertainty with this new technology, as well as cultural 'distance' from it expressed by local players.

The electronic conference papers by Bongsug Chae on dynamic institutional theory, Baltazar Chilundo and Margunn Aanestad on vertical and integrated health programmes, Evangelia Kopanaki and Steve Smithson on inter-organizational systems, Renata Lèbre La Rovere on information management networks, Carmen Joham and Junilee Pradhan on IT acquisition, Ann C. Séror on virtual institutional infrastructures, as well as Andrew Stein et al. on ERP implementation contribute to this theme.

\subsection{ICT Industries and Systems Development}

Aini Aman and Brian Nicholson address in their study the global software industry. They examine offshore software development commissioned by UK companies to Malaysian firms. They wish to explore and discuss a broad range of characteristics of the client - offshore vendor relationship, and to this end they exploit the COCPIT framework. They propose a new contingency framework that can be used to monitor and 'explain' managerial situations in offshore software development outsourcing.

Ping Gao and Kalle Lyytinen study telecommunications transformation in China. They interpret current reform initiatives in this context through Giddens' structuration theory perspective. Their analysis of how signification, domination and legitimation evolve over time is juxtaposed with related telecommunications strategy reform actions. This study investigates a major market change phenomenon from the perspective of the behaviour of decision makers in a path dependent process The insights gained may help us understand the future market reform decisions of this major international player.

Ciara Heavin, Brian Fitzerald, and Eileen Trauth trace the evolution trajectory of Ireland's software industry. They develop a comprehensive analysis framework by synthesizing extant literature on IT industry strategy, and development in the context of developing economies. They apply their conceptual framework on empirical evidence to illustrate how each of their proposed factors has been contributing to the industry's evolution and to recommend strategy directions for further consideration.

Jan Pries-Heje, Richard Baskerville and Galina Hansen examine the adoption of high-speed software development practices in Russia. Their 
study sheds light in an important economy under development and its local adaptation of global software practices. Using extant theory on the enablers of software practice diffusion, they analyze four Russian software firms in terms of their software development practice trajectories. They apply an organizational development perspective to conclude that barriers to the diffusion of practices are related to language, the 'youth' of Russian software firms, leadership challenges, and the effects of extensive foreign outsourcing.

S.K. Puri and Sundeep Sahay tackle the pervasive issue of participation in IS development in the context of GIS projects aiming to support the implementation of development related policies in India. In two GIS implementation case studies, they contrast phenomena reflecting the centrality of project control with the need to promote substantial user involvement, not least for effective harnessing of local, indigenous knowledge. Using the reflexive lens on institutional structure versus human, participatory agency, they interpret contrasting situations regarding GIS implementation scenaria by focusing on the interplay between 'scientific' and 'indigenous' knowledge dominance, and alternative views of management agency.

This theme is also addressed by the electronic conference papers by Pamela Y. Abbott on software outsourcing, Marisa D'Mello on global software organizations, Gaye Kiely and Brian Fitzgerald on the use of methods in IS development projects, Anja Mursu et al. on methods for sustainability in IS development, Brian Nicholson and Erran Carmel on offshore software development, as well as Rajeev Sharma and S. Krishna on global software work.

\subsection{Societal Dynamics}

Tony Cornford and Ela Klecun-Dabrowska deal with questions of social (in)exclusion in the context of community information systems that support healthcare needs in a London geographic community. They argue that the relative dearth of solid ideas and debate regarding 'informational responses' to social exclusion is manifest in the domination of 'technology as a solution to access problems' type of thinking. Their extensive case study in the London Borough of Lewisham questions the value of focusing on consequences when examining the impact of ICTs on exclusion. They propose a process driven line of thinking, focusing on the need to embed such ICT interventions in a wider agenda of sustained regeneration and reform of the related institutional framework.

Justine Johnstone examines the evolving character of non-governmental development organizations as active knowledge agents within a variety of policy influencing and development processes. She documents knowledge 
roles implicit in the current behaviour of such agencies focusing on their informational, epistemic and conceptual elements. Johnstone suggests that these three dimensions can aid NGOs reflect on their approach and practice. She illustrates further her point by suggesting how these three dimensions can help NGOs frame their use of networking technologies to augment their core competencies.

Tony Salvador, John Sherry and Alvaro Urrutia discuss in their work the role of shared models of ICT access (telecenters, cyber-cafes) as means for easing the digital divide. Their ethnographic study of cyber-cafes and traditional cafes in six countries across the globe illustrates the 'social' nature of these places and contrasts this with design maxims of functionality and efficiency dominating the set-up of some of these places. They argue in favour of an evolutionary approach in the set-up and running of these settings more akin to local characteristics of social life than to the technological options available.

Craig Standing, Ian Sims, Rosemary Stockdale, and Arjen Wassenaar are debating the capacity of government sponsored emarketplaces to act as bridges of the digital divide experienced by small and medium size firms in the Australian context. They raise questions related to the capacity of such firms to reap the benefits of participation in such digital network arrangements and explore them in the context of two cases, a central and a regional government marketplace initiative. Factors emerging through this study include shared ownership structures, the move from transaction to collaboration and information sharing business models, and the need to provide a wider rationale for marketplace development beyond narrow conceptions of direct economic returns.

Prodoromos Tsiavos, Ian Hosein and Edgar Whitley debate the relationship between technology and jurisdiction. They exemplify their discussion through the case of copyright and peer-to-peer technologies in conjunction with the regulatory environments surrounding their control, at various stages of such technologies' development. In their review, the existing schools of thought on the relationship between technology and regulation are either calling for mere replication of current regulatory thinking into digital spaces, or calling for fundamental regulatory reform. The authors move on to make the case for a third option: the co-evolution of technology driven regulatory change and of established legal practices.

The electronic conference papers contributing to this theme include the ones by Elaine Byrne and Sundeep Sahay on participation in primary health care information systems, Shirin Madon on e-governance, Alexander Osterwalder on ICT in developing countries, as well as Elpida Prasopoulou and Athanasia Pouloudi on IT as a stabilization mechanism in strategic alliances. 


\subsection{Cultural, Philosophical and Policy Issues}

Chrisanthi Avgerou in her paper reviews the historical trajectory of thinking that has linked ICTs and economic development within the discourse of international development agencies. She examines four recent influential publications on this topic, arguing that they all focus on the reciprocality between the development of conditions that foster ICT innovation, and the creation of an effective market. Avgerou reveals the controversy surrounding economic theories of development that are the theoretical foundations on which such current discourse has been based. She argues in favour of socio-economic theory of development as more appropriate for this discourse as it reflects the dynamics of ICT and development, "a situated, context-specific process that is entangled with indigenous politics and historically-formed institutions".

Claudio Ciborra and Diego Navarra debate dominant policy rhetoric promoting the use of ICTs to improve state governance practices as a lever for development in late developing countries. They look into the case of Jordan's e-government policy through the lens of New Institutional Economics, as the links between enforcement-transition costs and the outcomes of policies and interventions. Their analysis sensitizes us to the complex web of factors intervening between e-government implementation and effective governance, making a clear case against beliefs that effective governance capacity can be substituted for all-encompassing ICT interventions.

Kenneth Kendall, Julie Kendall and Muhammadou Kah approach the issue of ICT policy development for developing countries from a discourseanalytic perspective. Using Web discussion lists for relevant discursive material, they propose a 'dramatistic analysis' method aiming to illustrate the dynamics underlying sustainable policy development.

Mike Metcalfe and Carmen Joham in their paper attempt to break the dominant mould of thinking and research on knowledge sharing. They point our attention to patterns of knowledge exchange away from the exchange of written knowledge, towards the oral and the visual domains. They review the challenges that these forms of knowledge exchange introduce for the design of technical systems and then they augment their position with the cultural and social aspects pertinent to these situations. Their empirical context is a project aiming to support remote aboriginal communities in their exchanges with state government. Their study recommends useful enhancements to knowledge sharing facilities of dominant technological infrastructures, such as the Internet.

Gamila Shoib and Joe Nandhakumar deal with IS implementation in 'non-Western' contexts. Their argument is that 'Western' technologies carry with them a particular rationality that is incongruent with respect to the local 
context of implementation. They reflect on two large-scale case studies to illustrate the situated nature of rationality regarding IS implementation decisions. They indicate some problematic aspects of dominant rationality in the context of their topic, namely the treatment of technology as uniformly superior, the treatment of success as an 'absolute construct', the shallow understanding of human agency, and the futility of the 'West/non-West' dichotomy itself.

This theme is also studied in the electronic conference papers by Saheer Al Jaghoub and Christopher Westrup on building software industry and the role of nation state, Dimitrios A. Brachos on digital divide, Peter Meso et al. on the diffusion of national IT policies, as well as Jill Slay et al. on understanding "culture" in IS security research.

\subsection{Panels}

Robert Davidson, Ernest Jordan, Carol Hsu and Chrisanthi Avgerou in their panel discuss issues of professionalism in the IS domain. Particularly they wish to explore the role of professional societies in the promotion of a 'global' set of IS professional norms, a stance on which they apply a cautious outlook as they indicate the danger of over-westernization of the global community's perspective on IS professions.

Joseph Feller, Brian Fitzgerald, Jan Ljunberg, and Magnus Berquist's panel on open source and free software casts a wide net over this hot topic for economies under development. They wish to explore the ethos characterizing these development communities, the economic, business and societal rationales underlying their existence, forms of collaboration and knowledge sharing developed in them. The panelists also promise to cast their attention on the philosophical foundations of the debate on open source and free software as a public good.

\section{CONCLUSION}

As technology becomes more pervasive and capable, there is a danger that the debate will remain anchored on techno-centric issues as to what to use the technology for, or how to make it work. This book provides rich insights on how global technology in action must be considered in view of local expectations and constraints. This is particularly relevant in the current discourse relating technology to development - the theme permeating most of the works included in this volume. Research reported in this book achieves in our view a number of important objectives. It illustrates local ICT utilisation and policy development contexts that are not as frequently examined as North American and Western European corporate contexts. The 
research papers included exemplify the role of social theory in approaching ICT utilisation challenges in a globalisation context. The debates raised on implementation, policy, organisations and organising, and on social dynamics, increase our awareness on the diversity of perspectives we need to delve upon when framing the role of ICTs in the globalisation agenda. The equal representation of managerial and non-managerial decision making contexts alerts us to the fact that ICTs should not be considered only as a corporate wealth creation prerogative.

Social actors, managers, and researchers are faced with great challenges and opportunities in the development and use of information systems. However, making fashionable commitments and investments for their countries and organizations without systematically analyzing needs and individual and environment characteristics is irresponsible. If relevant stakeholders fail to understand the role of ICTs in accordance with their situations and idiosyncrasies, it will only create new barriers, limitations, and foreign necessities in their societies. We have to identify the extent to which countries and organisations must follow existing models or develop new ones.

We hope that the collection of papers in this book provide a deeper understanding and appreciation of this area, and thereby stimulate further research and discussions. This book has important implications for both research and practice. It is significant in that it represents one of the few books to consider information systems in the context of globalization. For practitioners, it provides useful insights. There is a qualitative difference in the approaches that have been followed. Given that there are no universal sources of advantage, social welfare, or individual well being, and that there are no two countries alike, additional research holds the promise of helping us unravel the dynamics of the global versus local, and of uniformity versus diversity regarding ICT adoption.

\section{REFERENCES}

Avgerou, C., and Walsham, G. (eds.) Information Technology in Context: Implementing Systems in the Developing World, Aldershot: Ashgate, 2000.

Avison, D., Kendall, J. E., and DeGross, J. I. (eds.) Human, Organizational, and Social Dimensions of Information Systems Development, Amsterdam: Elsevier, 1993.

Bhatnagar, S. C., and Bjørn-Andersen, N. (eds.) Information Technology in Developing Countries, Amsterdam: Elsevier, 1990.

Mumford, E., Hirscheim, R., Fitzgerald, G., and Wood-Harper, T. (eds.) Research Methods in Information Systems, Amsterdam: Elsevier, 1985.

United Nations, The Application of Computer Technology for Development: Second Report of the Secretary-General, UN Publication E.73.II.A.12, 1973.

Walsham, G. "Globalization and IT: Agenda for Research", in Organizational and Social Perspectives on Information Technology, R. Baskerville, J. Stage, and J. I. DeGross (eds.), Boston: Kluwer Academic Publishers, 2000, pp. 195-210. 


\section{About the Authors}

Mikko Korpela is Research Director of the Healthcare Information Systems R\&D Unit, University of Kuopio, Finland, and Docent at the Department of Computer Science at the same university. He was born in Finland and achieved his DTech in Information Systems at the Helsinki University of Technology in 1994. He was a Visiting Researcher at the Obafemi Awolowo University, Nigeria, for 1989. Later he was founding Secretary of IFIP WG 9.4 and an initiator of the Health Informatics in Africa (HELINA) conferences. He is member of IFIP WG 8.2 and AIS as well as Chair of Finnish Social and Health Informatics Association. His research interests include West African political history, activity development and information systems development particularly in healthcare. Mikko can be reached by e-mail at mikko.korpela@uku.fi or through his home page at http://www.uku.fi/ korpela.

Ramiro Montealegre is an Associate Professor of Information Systems at the University of Colorado, Boulder, and a Visiting Professor at Instituto de Empresa in Madrid. He was born in Guatemala, and achieved his Bachelor in Engineering degree from Francisco Marroquín University, Guatemala. His master's degree in Computer Science is from Carleton University, Canada. He received his Doctorate in Business Administration from the Harvard Business School in Management Information Systems. His research focuses on the interplay between information technology and organization transformation in highly uncertain environments. Ramiro can be reached by e-mail at Ramiro.Montealegre@colorado.edu or through his home page at http://leeds.colorado.edu/interactive /employees / profiles / show.cfm?id=1323

Angeliki Poulymenakou is Assistant Professor in Information Systems in the Department of Management Science and Technology of the Athens University of Economics and Business. Prior to that she has served as lecturer in the Information Systems Department of the London School of Economics and Political Science. She is an academic member of ELTRUN, the e-business research centre of the AUEB. She holds a first degree in Mathematics (Athens), and MSc and PhD degrees in Information Systems (London School of Economics). Her current research interests focus on the study of technological intervention in the areas of organisational learning and knowledge management, and on the study of dynamic organisational networks from an information systems perspective. Angeliki can be reached by e-mail at akp@aueb.gr. More information on her activities can be found at http://www.eltrun.aueb.gr. 